\title{
Active non-operative treatment of acute isolated posterior cruciate ligament injury with cylinder cast immobilization
}

Young Bok Jung · Suk Kee Tae $\cdot$ Yong Seuk Lee $\cdot$
Ho Joong Jung $\cdot$ Chang Hyun Nam $\cdot$ Se Jin Park

Published online: 19 September 2008

(C) Springer-Verlag 2008

Erratum to: Knee Surg Sports Traumatol Arthrosc

(2008) 16:729-733

DOI 10.1007/s00167-008-0531-0

Unfortunately, we had indicated the incorrect affiliation for the corresponding author. The correct affiliation is now indicated below.

The online version of the original article can be found under doi:10.1007/s00167-008-0531-0.

Y. B. Jung · H. J. Jung · C. H. Nam · S. J. Park

Department of Orthopedic Surgery, Chung-Ang Medical Center,

Heukseok-dong 224-1, Dongjak-gu, Seoul, South Korea

Y. S. Lee $(\bowtie)$

Department of Orthopaedic Surgery,

Korea University Ansan Hospital, 516 Gozan-dong,

Danwon-gu, Ansan 425-707, South Korea

e-mail: smcos1@hanmail.net

S. K. Tae

Dong-Kuk University Ilsan Hospital, Ilsan, South Korea 